\title{
UTILIZAÇÃO DE MISTURAS DE CAVACOS INDUSTRIAIS COM RESÍDUOS DE SERRARIA PROVENIENTES DE MADEIRAS DE Eucalyptus grandis DE DIFERENTES IDADES PARA PRODUÇÃO DE PASTA KRAFT
}

\author{
UTILIZATION OF MIXTURES OF INDUSTRIAL WOOD CHIPS AND SAWMILL RESIDUES OF \\ Eucalyptus grandis OF DIFFERENT AGES FOR KRAFT PULP PRODUCTION
}

\author{
Angelina Maron ${ }^{1}$ José Mangolini Neves ${ }^{2}$
}

\section{RESUMO}

Este trabalho estuda a viabilidade técnica do uso conjunto de resíduos de serraria (costaneiras dentre outros) e topos de árvores de Eucalyptus grandis com 15 anos de idade, destinadas à produção de madeira sólida, com madeira de árvores de plantio industrial, com 7 anos de idade, destinadas à produção de pasta kraft. São apresentados modelos úteis à realização de estimativas de alturas total e comercial e de volumes de madeira comercial e adequadas para serraria, todos baseados no DAP. São fornecidos dados anatômicos, de densidade básica e de composição química de misturas desses tipos de materiais. Mostra-se que é tecnicamente viável realizar deslignificações kraft com misturas contendo madeira comercial de Eucalyptus grandis 7 anos com resíduo de serraria ou topos de árvores. A deslignificação kraft de resíduos de serraria resulta em perda rápida de rendimento, mas a pasta produzida sob as mesmas condições apresenta número Kappa menor que a de Eucalyptus grandis com 7 anos. A deslignificação de topos de árvores resulta em perda de rendimento bruto, mas o consumo específico de madeira é menor. Conforme aumenta a madeira de topo nas misturas, ocorre um aumento na densidade básica, o comprimento médio das fibras fica praticamente o mesmo e um pequeno aumento no teor de lignina; há diminuição nos extrativos em etanol, em água quente e na solubilidade em $\mathrm{NaOH} 1 \%$. Diminui um pouco o rendimento bruto em pasta, mas praticamente não afeta o número Kappa, caindo sensivelmente o consumo específico de madeira. Com o aumento de madeira de resíduo de serraria das árvores nas misturas, praticamente não há efeito sobre a densidade básica, mas o comprimento médio das fibras aumenta, ocorrendo também um pequeno aumento no teor de lignina. Os extrativos em etanol, em água quente e na solubilidade em $\mathrm{NaOH} 1 \%$ diminuem. $\mathrm{O}$ rendimento bruto em pasta cai um pouco, mas com uma queda sensível no número Kappa, sem afetar praticamente o consumo específico de madeira. Em suma, para um mesmo número Kappa, as condições de cozimento podem ser menos drásticas para se obter um mesmo resultado final, podendo significar uma redução no consumo de reagentes durante seu processamento. E como o comprimento médio das fibras sofreu um pequeno acréscimo, a pasta resultante certamente apresentará maior resistência mecânica e, conseqüentemente, um papel de melhor qualidade.

Palavras-chave: Eucalyptus grandis; resíduo de floresta; resíduo; celulose kraft.

\section{ABSTRACT}

This work studies the technical viability of using mixtures of sawmill residues (slabs and others) and tree tops of 15 years old, with industrial wood chips, 7 years old, Eucalyptus grandis in the production of kraft pulp. Models were prepared to estimate total and commercial heights and commercial volumes adequate to sawing, all based on DBH. Anatomical data, wood densities and chemical composition of these mixtures are provided. The study shows that it is technically viable to perform kraft delignifications with these mixtures. The use of sawmill residues results in a fast yield loss but the pulp produced under the same conditions yields lower Kappa number than that obtained with 7 year-old Eucalyptus grandis. The delignification of tree tops results in the loss of gross yield, but the specific wood consumption is smaller. As the wood of tree tops increase, there is an increase of the wood density, the fiber average length remains practically the same and a small increase is obtained in the lignin content, but there is a decrease of extractives in ethanol, in hot water and in the solubility in $\mathrm{NaOH} 1 \%$. The gross yield in pulp decreases slightly, but does not practically affect the

1. Engenheira Florestal, Mestranda na Área de Ciência e Tecnologia da Madeira pela Escola de Agricultura "Luiz de Queiroz". Técnica da Empresa Kimberlay Clark Kenko. amaron @kcc.com

2. Engenheiro Químico, Dr., Professor Adjunto do Departamento de Engenharia Química da EPUSP, Pesquisador do Instituto de Pesquisas Tecnológicas do Estado de São Paulo - IPT/DPF, Agrupamento Celulose e Papel, Av. Prof. Almeida Prado, 532, Cidade Universitária, Bairro Butantã, Prédio 62, CEP 05508-901, São Paulo (SP). 
Kappa number, the specific wood consumption falling sensibly. The sawmill residues increase in the mixtures practically does not affect the wood density, but the fiber average length increases, also with a small increase in lignin content. Extractives in ethanol, hot water and the solubility in $\mathrm{NaOH} 1 \%$ decrease. The gross yield in pulp falls a lightly, but with a significant fall in the Kappa number, without practically affecting the specific wood consumption. In short, for the same Kappa number, cooking conditions can be less drastic to obtain the same final result, since it possibly means a reduction in reagent consumption during the process. And as the fiber average length showed a small increase, the resulting pulp will certainly yield a higher mechanical resistance and consequently, a better quality paper.

Key words: Eucalyptus grandis; forest residue; residue; kraft pulping.

\section{INTRODUÇÃO}

No Brasil, a madeira originária de floresta plantada quase em sua totalidade se destina às companhias de celulose e de chapas. A produção de celulose está concentrada no processo sulfato ou kraft de Eucalyptus spp, produzindo pasta ou celulose branqueada de fibras curtas.

Entretanto, apesar do setor celulósico ser muito organizado e a projeção de demanda indicar um futuro promissor, é conhecido que essa demanda é cíclica e apresentou um mínimo entre os anos de 1990 e 1993 , situação criada pelo excesso de oferta de pasta no mercado internacional. Essa situação deixou marcas negativas que têm estimulado a procura de opções para um uso mais variado da floresta, especialmente daquelas plantadas exclusivamente para produção celulose, definindo o que se conhece hoje por "uso múltiplo da floresta". Passou-se também a fomentar uma produtividade florestal e rendimento industrial maiores.

Atualmente, as companhias de celulose têm usado em seus processos madeira produzida em plantações de Eucalyptus spp, com cerca de 7 anos de idade. Porém, a possibilidade futura de uma nova retração econômica com uma situação de demanda mínima de celulose tem levado as companhias desse setor produtivo a procurarem modos mais flexíveis de administrarem suas florestas, mormente com relação às possibilidades de destinar, pelo menos, parte das madeiras resultantes para outros fins, contudo sem afetar as características de qualidade exigidas para a produção de celulose.

Uma das opções é o uso múltiplo da floresta, destinando, pelo menos, parte dela à produção de madeira sólida para a construção civil ou para móveis. A madeira, nesses casos, deve apresentar grandes diâmetros e, para isso, tem que ficar mais tempo no campo, de modo a alcançar volumes maiores que os obtidos usualmente na indústria de celulose. Mas, mesmo assim, surgem as seguintes perguntas que devem ser respondidas: 1) O uso mais racional da floresta será possível sem afetar a qualidade final do produto "celulose "?; e 2) Quais são as formas mais apropriadas de uso da madeira obtida?

Há ainda o problema referente ao que fazer com os resíduos de madeira, tidos como o material excedente de um processamento o qual pode ser de vários tipos, gerando uma diferenciação quanto à composição do resíduo. O resíduo florestal é o material excedente da operação de extração das árvores nas florestas, sendo constituído por partes quebradas de árvores, toras que não atingiram dimensões mínimas de uso (5 $\mathrm{cm}$ de diâmetro) e as partes superiores das árvores (pontas) (Estep, s.d.).

Produzir madeira sólida também gera resíduos de madeira, definidos como resíduos primários por resultarem de operações de transformação da madeira como, por exemplo, no desdobro em serraria, quando se geram os resíduos de serraria, compostos por costaneiras, serragem, entre outros (Estep, s.d.).

O próprio termo "resíduo" está normalmente associado à palavra "problema". Sua disposição ou o seu uso de um modo mais apropriado normalmente implica em custos altos que as companhias querem evitar. Porém, quanto mais informações e conhecimento sobre os problemas inerentes à sua geração, de suas características, da qualidade que pode ser obtida e das quantias envolvidas, maiores serão as chances de um uso mais adequado desses materiais. Poderão, assim, surgir opções que tornem mais rentáveis o próprio manejo florestal. Nos Estados Unidos, grande parte desses resíduos são consumidos pelas indústrias de celulose e de chapas (Estep, s.d.).

Para produção de madeira sólida é conveniente que se trabalhe com árvores mais velhas, pois 
apresentam diâmetros maiores, o que permite o desdobro em tábuas mais largas e com maior valor agregado. Outra vantagem é que a madeira já estabilizou sua estrutura em termos de alívio de tensões internas. Os topos dessas árvores, por apresentarem diâmetros entre 5 e $30 \mathrm{~cm}$, fornecem tábuas ou irregulares ou de largura pequena e, por isso, destinam-se mais à produção de pontaletes e caibros de baixo valor agregado, mas que podem tornar-se uma fonte de celulose.

De acordo com Foelkel et al. (1978), toda vez que um tronco é serrado, forma-se entre 2 e 5\% de serragem, baseado na massa seca da madeira. Perez Jara (1995) informou que durante o desdobro de madeira são produzidas entre 20 e $25 \%$ de serragem e cerca de $50 \%$ de madeira serrada. Como a medição desse material é difícil, Casey (1980) recomenda usar a correspondência de que $1 \mathrm{~m}^{3}$ de madeira sólida equivale à produção de 2,26 $\mathrm{m}^{3}$ empilhados de serragem mais 2,0 $\mathrm{m}^{3}$ empilhados de cavacos que podem ser obtidos dos resíduos de serraria. Fisher (1978) comenta que num processo regular, com esse volume de madeira são obtidos 2,5 $\mathrm{m}^{3}$ de cavacos. A serragem embora possa ser usada (Casey, 1980), não é aceita na produção de pasta kraft (Forest Products Laboratory, 1964), mas pode ser queimada para gerar gases quentes a serem usados em secagem de madeira serrada (Neves, 1980).

As características da madeira contida nesses resíduos podem tornar-se uma ótima oportunidade a ser explorada, sobretudo quanto à densidade básica e aspectos físicos e químicos. Essas características são bastante complexas, resultando da combinação de vários fatores genéticos, ambientais e de adaptabilidade.

Quanto à densidade básica, Barrichello et al. (1986) comentam que nas várias espécies de Eucalyptus essa característica, na direção da base para topo da árvore, tende a diminuir da base até o DAP e que tende a aumentar daí para o topo. Manfredi (1985) observou que essa densidade, ao longo de um tronco de Eucalyptus grandis com 7,5 anos de idade, diminuía fortemente da base até os $10 \%$ finais de sua altura total e, então, começava a aumentar linearmente até o topo apresentando valores maiores que os do tronco. Também foi observado por Foelkel et al. (1971) e por Manfredi (1985) que a variação da densidade básica na direção base-topo segue um modelo quadrático, com valores mais altos na base e no topo das árvores.

Por outro lado, o próprio tronco de uma árvore pode ser dividido em duas áreas, uma mais próxima ao cerne, originária do crescimento inicial, denominada madeira juvenil, e outra, mais externa, denominada madeira adulta. Jankowsky (1979) comenta que o tronco apresenta um tipo de cilindro no centro da árvore. Essa parte apresenta características juvenis que se estendem da base ao topo, podendo-se concluir que o topo das árvores contém essencialmente madeira juvenil. Esta apresenta fibras mais curtas, com paredes mais finas e densidade baixa, alto teor de lignina e muita madeira de reação (Foelkel e Barrichello, 1975). Hillis e Brown (1984), por sua vez, comentam que a porcentagem de extrativos tende a aumentar no sentido cerne-casca e diminuir no sentido base-topo. Panshin e Zeeuw (1970) comentam que os componentes químicos também variam percentualmente dentro de uma árvore.

Isso é mais evidente no caso das coníferas. Hatton (1997) mostrou que madeira juvenil de coníferas, quando comparada à madeira adulta, apresenta densidade básica menor, fibras com comprimento menor, enquanto os teores de lignina, extrativos e solubilidade em soda são maiores.

Assim, de um modo geral, pode-se esperar que em árvores de idades diferentes e, por conseguinte, com volumes e massas diferentes, ocorram diferenças de densidade, composição química e características anatômicas.

Em termos de cozimento kraft, Foelkel e Barrichello (1975) e Foelkel (1978) comentam que a madeira mais adequada para cozimento é aquela que apresenta densidade básica ao redor de $0,5 \mathrm{~g} / \mathrm{cm}^{3}$, índice de Runckel menor que um, fração de parede até $40 \%$, coeficiente de rigidez sobre $60 \%$, baixa porcentagem de parenquima, ou seja, no caso de folhosas, os elementos de vasos com menor diâmetro e baixa frequiência.

Assim, este trabalho tem a intenção de fornecer dados que contribuam à resolução de problemas de usos mais adequados para as madeiras das florestas existentes. Procurou-se verificar a viabilidade técnica de se produzirem madeira sólida e pasta kraft com uma população de Eucalyptus grandis, com 15 anos de idade, originalmente destinada ao aproveitamento integral como madeira sólida, procurando aproveitar também os resíduos florestais, topos de árvores e resíduos de serraria. O trabalho se dividiu em duas fases: uma, em que se verificou o aproveitamento da madeira para serraria; e, outra, na qual se testou a viabilidade de 
aproveitamento na produção de pasta kraft desses materiais só ou em mistura com madeira do mesmo tipo de eucalipto, mas com 7 anos de idade, regularmente usada em uma fábrica de celulose.

\section{MATERIAIS E MÉTODOS}

Para a realização de primeira fase deste trabalho, a madeira foi coletada em uma plantação comercial de Eucalyptus grandis ex Coff's Harbour, em Passo da Estância, distrito de Barra do Ribeiro (RS), pertencente à Companhia Riocell. Essa plantação foi manejada com o propósito de se obter madeira serrada, plantada em 1981, teve seu primeiro desbaste em 1987; o segundo, em 1988; o terceiro, em 1989; sendo abatida em 1996, com 15 anos. De um talhão (19,5 ha), nove árvores foram coletadas ao acaso e separadas igualmente em três amostras: A, B e C, como mostrado na Figura 1.

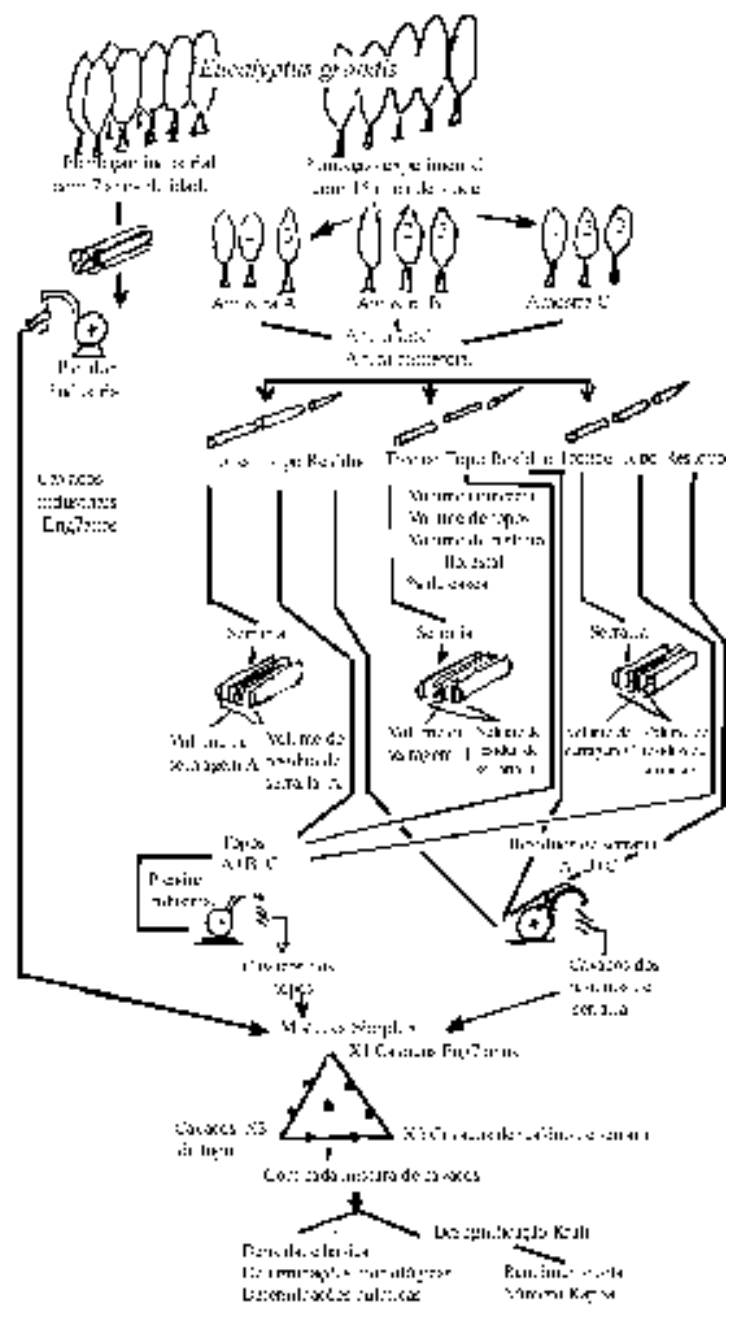

FIGURA 1: Esquema da coleta e da preparação das amostras.

FIGURE 1: Lay-out for sample collection and preparation.

Depois do corte, em cada árvore foram mensuradas as alturas total e comercial (até diâmetro mínimo de $5 \mathrm{~cm}$ ), mais o teor de casca. As partes das árvores com diâmetro maior que $30 \mathrm{~cm}$ no DAP (diâmetro a altura de peito) foram cortadas em troncos com 4,2 $\mathrm{m}$ de comprimento e destinadas à serraria. Os troncos descascados tiveram os diâmetros máximo e mínimo medidos e foram posteriormente serrados em tábuas, que foram medidas quanto à largura e comprimento. A serragem foi coletada e teve seu volume medido.

Foram determinados: 1) o Volume adequado para serraria, Vas , $\mathrm{m}^{3}=[(\mathrm{Ss}+\mathrm{Sb}) / 2] \mathrm{L}$, em que: $\mathrm{Ss}=$ $\left[\left(\pi \mathrm{Ds}^{2}\right) / 4\right]$; Ds = diâmetro menor, $\mathrm{cm} ; \mathrm{Sb}=\left[\left(\pi \mathrm{Db}^{2}\right) / 4\right] ; \mathrm{Db}=$ diâmetro maior, cm; e, $\mathrm{L}=$ comprimento de tronco, $\mathrm{m} .2)$ Volume de tábuas, $\mathrm{Vt}, \mathrm{m}^{3}=(1 . \mathrm{t} . \mathrm{w}) \mathrm{n}$, em que: $\mathrm{l}=$ comprimento, $\mathrm{m} ; \mathrm{t}=$ espessura, $\mathrm{m} ; \mathrm{w}=$ 
largura, m; e n = o número de tábuas; 3) Rendimento na serraria, \% =(Vt/Vas $) 100$.

Como o DAP é uma característica fácil de ser medida na floresta, procurou-se estabelecer entre este e os dados levantados modelos para se estimar para as árvores suas alturas total e comercial e seus volumes comercial, adequados para serraria e de topos. Como se dispunha de um número baixo de observações (nove árvores), foi usada a técnica "Jackfine" para estimar os coeficientes dos modelos, como recomendado por Schreuder e Brinck (1983).

Para realização da segunda fase deste trabalho, os resíduos de serraria foram transformados em cavacos em um picador Carthage de três facas, formando as amostras: $\mathrm{RS}_{\mathrm{A}}, \mathrm{RS}_{\mathrm{B}}$ e $\mathrm{RS}_{\mathrm{C}}$. As partes das árvores com diâmetros entre 5 e $30 \mathrm{~cm}$, os topos foram cortados em troncos de $2,2 \mathrm{~m}$ de comprimento que foram descascados, medidos e também transformados em cavacos, gerando as amostras: $\mathrm{TP}_{\mathrm{A}}, \mathrm{TP}_{\mathrm{B}}$ e $\mathrm{TP}_{\mathrm{C}}$. Essas amostras foram misturadas para formar as amostras de cavacos que foram denominadas, respectivamente, "resíduo de serraria" e "topo". Os cavacos industriais usados neste trabalho foram obtidos de madeira de Eucalyptus grandis com 7 anos de idade, formando a amostra "Eg".

Com essas três amostras de cavacos foram preparadas dez misturas de acordo com um delineamento simplex cúbico centrado que tiveram suas características físicas, anatômicas e químicas analisadas e depois foram submetidas a experimentos de cozimento kraft.

A densidade básica das amostras foi determinada pelo método do máximo teor de umidade (Foelkel et al., 1971). As análises morfológicas foram feitas em material separado de cada mistura de madeira que foi transformada em palitos e amolecido em solução de ácido acético glacial e peróxido de hidrogênio a 30 volumes, na proporção de 1:1. Depois de 24 h, a solução foi escoada e o material sólido amolecido foi lavado várias vezes com água, sendo depois tratado com safranina. De cada amostra, foram montadas cinco lâminas, sendo feitas em cada uma trinta determinações de cada elemento anatômico.

A caracterização química de cada mistura foi feita em amostra de serragem (fração 40/60 mesh) obtida pela passagem dos cavacos em moinho Wiley. As análises feitas foram as seguintes: solubilidade em água quente (NBR 7988); solubilidade em NaOH 1\% (NBR 7990); extrativos (NBR 7991); lignina Klason (TAPPI T 222); cinzas (TAPPI T 211); holocelulose $(\mathrm{H})$ por diferença onde $\% \mathrm{H}=[100-(\% \mathrm{ET}+\% \mathrm{~L})]$, sendo ET, extrativos totais e L, lignina Klason.

As principais relações entre os elementos anatômicos foram obtidas usando as seguintes fórmulas: FP, poder de enfeltramento $=(\mathrm{L} / \mathrm{D}) \times 1000 ; \quad \mathrm{FR}$, relação de flexibilidade, $\%=(\mathrm{LD} / \mathrm{L})$ x100; WF, fração de parede, $\%=(2 \mathrm{~W} / \mathrm{D}) .100 ; \quad \mathrm{IR}$, índice de Runckel $=(2 \mathrm{~W} / \mathrm{LD}) ; \mathrm{L}=$ comprimento da fibra, $\mathrm{mm} ; \mathrm{D}=$ diâmetro da fibra, $\mu \mathrm{m} ; \mathrm{LD}=$ diâmetro do lumen, $\mu \mathrm{m} ; \mathrm{W}=$ parede da fibra, $\mu \mathrm{m}$.

Deslignificações kraft foram realizadas em um digestor rotativo de aço inox. As condições foram: $14 \%$ de álcali ativo, como $\mathrm{Na}_{2} \mathrm{O} ; 25 \%$ de sulfidez; relação licor/madeira de 4:1; tempo até temperatura máxima igual a 60 minutos; temperatura máxima de $170^{\circ} \mathrm{C}$ e 30 minutos a essa temperatura. Essas condições são regularmente usadas na indústria que forneceu a madeira industrial.

Misturas preparadas com cavacos "resíduo de serraria", "topo" e "Eg" foram colocadas em células para deslignificação simultânea sob as mesmas condições, sendo que em cada uma foi colocado o equivalente a $30 \mathrm{~g}$ de cavacos secos. Dois cozimentos kraft foram realizados e, em cada um, foram colocadas duas células com material de cada amostra. Após cozimento, o conteúdo de cada célula foi lavado, desintegrado e usado nas determinações de rendimento total em pasta e de número Kappa (NBR 7537).

As quantidades de pasta geradas foram insuficientes para a preparação de folhas manuais o que, consequientemente, impossibilitou a obtenção de dados sobre suas características físicas. Entretanto, pelas das relações entre os elementos anatômicos das fibras das pastas, pode-se obter dados sobre as prováveis características físicas de uma pasta kraft a ser preparada (Philipp, 1974). É conhecido que o poder de enfeltramento se correlaciona com a densidade da folha de papel, enquanto a flexibilidade e relações de Runckel se correlacionam com a flexibilidade e com o grau de colapso que as fibras podem apresentar depois do cozimento kraft, características que controlam a uniformidade na folha de papel. Também é conhecido que, quanto menor a fração de parede, maiores são a flexibilidade e a relação de Runckel, conferindo ao papel 
maiores resistências à tração, estouro e dobras duplas.

Construindo-se um gráfico em que os valores de poder de enfeltramento, FP, são contrastados com os de relação de flexibilidade, é possível agrupar as misturas com valores mais altos que $50 \mathrm{em}$ PF e $50 \%$, em FR. As pastas resultantes dessas misturas devem apresentar valores satisfatórios de resistência à tração e ao rasgo.

\section{RESULTADOS E DISCUSSÃO}

\section{Fase 1: Estimação do volume das árvores}

Na Tabela 1, são apresentados os dados obtidos no campo para a madeira com casca e na Tabela 2, para a madeira sem casca.

TABELA 1: Características das árvores com casca.

TABLE 1: Characteristics of the trees with bark.

\begin{tabular}{cccccccc}
\hline $\begin{array}{c}\text { Código da } \\
\text { Árvore }\end{array}$ & $\begin{array}{c}\text { DAP } \\
(\mathrm{cm})\end{array}$ & $\begin{array}{c}\text { Altura } \\
\text { Total } \\
(\mathrm{m})\end{array}$ & $\begin{array}{c}\text { Comercial c/casca } \\
\left(\mathrm{m}^{3}\right)\end{array}$ & \multicolumn{2}{|c|}{$\begin{array}{c}\text { Volume de Resíduo } \\
\left(\mathrm{F}^{3}\right)\end{array}$} & $\begin{array}{c}\text { Volorestal }^{2} \\
(\% \mathrm{v} / \mathrm{v})\end{array}$ & $\begin{array}{c}\text { Florestal Total }^{3} \\
\left(\mathrm{~m}^{3}\right)\end{array}$ \\
\hline A1 & 54,0 & 46,1 & 4,659 & 0,037 & 0,79 & 4,696 \\
A2 & 43,5 & 45,3 & 2,886 & 0,022 & 0,76 & 2,908 \\
A3 & 40,5 & 43,8 & 2,097 & 0,019 & 0,90 & 2,116 \\
B1 & 42,0 & 43,4 & 2,065 & 0,020 & 0,96 & 2,085 \\
B2 & 48,0 & 43,5 & 3,402 & 0,033 & 0,96 & 3,435 \\
B3 & 46,0 & 42,9 & 2,691 & 0,026 & 0,96 & 2,717 \\
C1 & 52,0 & 47,4 & 4,259 & 0,031 & 0,72 & 4,290 \\
C2 & 46,0 & 46,2 & 3,454 & 0,024 & 0,69 & 3,478 \\
C3 & 46,0 & 43,7 & 3,069 & 0,027 & 0,87 & 3,096 \\
\hline Média A,B,C & 46,4 & 44,7 & 3,176 & 0,027 & 0,84 & 3,202 \\
Total & - & - & 28,582 & 0,239 & - & 28,821 \\
\hline
\end{tabular}

Em que: 1 = Volume das árvores com diâmetro maior que $5 \mathrm{~cm} ; 2$ = Volume das partes das árvores com diâmetro máximo de $5 \mathrm{~cm} ; 3$ = Igual à soma de (1) e (2).

TABELA 2: Características das árvores sem-casca.

TABLE 2: Characteristics of the trees without bark.

\begin{tabular}{|c|c|c|c|c|c|c|c|}
\hline $\begin{array}{l}\text { Código } \\
\text { da Árvore }\end{array}$ & $\begin{array}{c}\text { Altura } \\
\text { Comercial }^{1} \\
(\mathrm{~m})\end{array}$ & $\begin{array}{c}\text { Volume } \\
\text { Comercial s/casca }{ }^{2} \\
\left(\mathrm{~m}^{3}\right)\end{array}$ & \multicolumn{2}{|c|}{$\begin{array}{l}\text { Volume de Madeira } \\
\text { Adequada } \mathrm{p} / \text { serraria }^{2}\end{array}$} & \multicolumn{2}{|c|}{$\begin{array}{c}\text { Topos das } \\
\text { Árvores }^{3}\end{array}$} & $\begin{array}{l}\text { Teor de } \\
\text { Casca } \\
(\% \mathrm{v} / \mathrm{v})\end{array}$ \\
\hline A1 & 42,90 & 4,03 & 3,8590 & 82,2 & 0,605 & 12,9 & 7,5 \\
\hline $\mathrm{A} 2$ & 41,90 & 2,67 & 2,0690 & 71,1 & 0,721 & 24,8 & 7,4 \\
\hline $\mathrm{A} 3$ & 40,70 & 1,89 & 1,1670 & 55,1 & 0,814 & 38,5 & 10,0 \\
\hline B1 & 39,90 & 1,89 & 1,0540 & 50,6 & 0,808 & 38,8 & 8,5 \\
\hline B2 & 40,30 & 3,13 & 2,5000 & 72,8 & 0,604 & 17,6 & 8,1 \\
\hline B3 & 39,30 & 2,46 & 1,8020 & 66,3 & 0,751 & 27,6 & 8,7 \\
\hline $\mathrm{C} 1$ & 44,40 & 3,86 & 3,3780 & 78,7 & 0,612 & 14,3 & 9,3 \\
\hline $\mathrm{C} 2$ & 43,10 & 3,21 & 2,5230 & 72,5 & 0,710 & 20,4 & 7,0 \\
\hline $\mathrm{C} 3$ & 41,00 & 2,76 & 2,2420 & 72,4 & 0,603 & 19,5 & 10,2 \\
\hline Média A,B,C & 41,50 & 2,87 & 2,2882 & 69,1 & 0,692 & 19,8 & 8,5 \\
\hline Total & - & 25,90 & 20,594 & - & 6,228 & - & - \\
\hline
\end{tabular}

Em que: 1 = Considerando as árvores com diâmetro até o mínimo de $5 \mathrm{~cm} ; 2=$ Considerando as árvores com diâmetro maior que $30 \mathrm{~cm} ; 3$ = Considerando as partes das árvores com diâmetros entre 5 e $30 \mathrm{~cm}$.

O resíduo de floresta, definido como a porção da árvore com diâmetro menor que $5 \mathrm{~cm}$ e que normalmente é deixado no campo, apresentou média global de $0,84 \%$ do volume total de madeira da floresta. 
Das Tabelas 1 e 2, têm-se que, da madeira original, $28,821 \mathrm{~m}^{3}$, foram obtidos $28,582 \mathrm{~m}^{3}$ de madeira comercial com casca, sendo possível separar $25,9 \mathrm{~m}^{3}$ de madeira comercial sem-casca, resultando em $20,6 \mathrm{~m}^{3}$ de madeira adequada para serraria, mais $6,228 \mathrm{~m}^{3}$ de topos de árvore.

A porcentagem de casca das árvores a várias alturas ficou entre 7 e 10,2\%. Para testar se há uma relação de independência entre a quantidade de casca e o DAP (diâmetro a altura de peito), foi usada a prova de independência descrita por Lehmann e D'Abrera (1975), pela estatística D. A estatística D é um método não-paramétrico, usado para testar se há uma relação de independência entre duas variáveis sobretudo quando se dispõe de poucos dados experimentais. No caso, foram submetidas à prova de independência as variáveis: DAP (diâmetro a altura de peito) cujos dados foram extraídos da Tabela 1, e de porcentagem de casca cujos dados foram tirados da Tabela 2.

No cálculo, D é igual a $\sum(\mathrm{Ri}-\mathrm{Sj})^{2}$, em que: $\mathrm{D}$ é usado para a prova de independência; Ri, são os valores (posição) da variável DAP ( $\mathrm{i}=1,2, \ldots, 9)$; e, $\mathrm{Sj}$, os valores (posição) da variável porcentagem de casca $(\mathrm{j}=1,2, . ., 9$ ). O nível de significância usado foi o de 5\% e o cálculo da probabilidade de significância foi feito por meio da aproximação pela curva normal. A significância foi feito mediante aproximação pela curva normal.

Na Tabela 3, temos os dados extraídos das Tabelas 1 e 2 e na Tabela 4, tem-se o cálculo de D.

Caso não houvesse repetição de resultados $(\mathrm{N}=9)$, os valores da esperança e da variância de $\mathrm{D}$ são calculados por:

$$
\begin{aligned}
& \mathrm{E}(\mathrm{D})=(1 / 6)\left(\mathrm{N}^{3}-\mathrm{N}\right)=(1 / 6)\left(9^{3}-9\right)=120 \\
& \operatorname{VAR}(\mathrm{D})=(1 / 36)\left[\mathrm{N}^{2}(\mathrm{~N}+1)^{2}(\mathrm{~N}-1)=1800\right.
\end{aligned}
$$

Mas como ocorreram três valores de DAP iguais (3), os valores de esperança e da variância de D devem ser corrigidos $(*)$, o que é feito do seguinte modo:

$$
\begin{aligned}
& \mathrm{E}\left(\mathrm{D}^{*}\right)=\mathrm{E}(\mathrm{D})-(1 / 12)\left(3^{3}-3\right)=119,5 \\
& \operatorname{VAR}\left(\mathrm{D}^{*}\right)=\left\{\operatorname{VAR}(\mathrm{D})-\left[1-\left(3^{3}-3\right)\right]\right\} /\left(9^{3}-9\right)=1800-0.9917 \sim 1799 \mathrm{e} \\
& \phi(\mathrm{z})=(\text { Valor observado de } \mathrm{D}-\text { Valor esperado de } \mathrm{D}) /\left(\mathrm{VAR}^{*}\right)^{0,5}=(138-119,5) /(1799)^{0,5}=
\end{aligned}
$$

TABELA 3: Ordenação dos dados $(\mathrm{N}=9)$.

TABLE 3: Data ranking $(\mathrm{N}=9)$.

\begin{tabular}{ccccccccccc}
\hline DAP $^{1}(\mathrm{~cm})$ & Ordem $^{1}$ & \%casca & Ordem $^{2}$ & DAP $^{2}(\mathrm{~cm})$ & Ordem $^{3}$ & \%casca $^{2}$ & Ordem $^{4}$ \\
\hline 54 & 9 & 7,5 & 3 & 40,5 & 1 & 7 & 1 \\
43,5 & 3 & 7,4 & 2 & 42 & 2 & 7,4 & 2 \\
40,5 & 1 & 10 & 8 & 43,5 & 3 & 7,5 & 3 \\
42 & 2 & 8,5 & 5 & 46 & $5^{*}$ & 8,1 & 4 \\
48 & 7 & 8,1 & 4 & 46 & $5^{*}$ & 8,5 & 5 \\
46 & 5 & 8,7 & 6 & 46 & $5 *$ & 8,7 & 6 \\
52 & 8 & 9,3 & 7 & 48 & 7 & 9,3 & 7 \\
46 & 5 & 7 & 1 & 52 & 8 & 10 & 8 \\
46 & 5 & 10,2 & 9 & 54 & 9 & 10,2 & 9 \\
\hline
\end{tabular}

Em que: $\mathrm{DAP}^{1}=($ Tabela $1-$ coluna 1$) ; \mathrm{DAP}^{2}=($ Ordenado de forma crescente $) ;$ Ordem $^{1}=($ posto - do dado na coluna $6(\mathrm{Ri})-$ coluna 2$) ;$ Ordem $^{2}=($ posto - do dado na coluna $8(\mathrm{Si})-$ coluna 4$) ;$ Ordem $^{3}=($ posto - do dado na ordenação da coluna 5 - coluna 6$) ;$ Ordem $^{4}=($ posto - do dado na ordenação da coluna $7-$ coluna 8$) ; \%$ casca $^{1}=($ Tabela $2-$ coluna 3$) ; \%$ casca $^{2}=($ Ordenado de forma crescente - coluna 7$) ; *$ posto médio.

TABELA 4: Cálculo de $\mathrm{D}$ para $\mathrm{N}=9$.

TABLE 4: $\quad \mathrm{D}$ calculations for $\mathrm{N}=9$.

\begin{tabular}{lrrrrrrrr}
\hline Ordem ( posto) do DAP, Tabela 3, Ri & 9 & 3 & 1 & 2 & 7 & 5 & 8 & 5 \\
\hline Ordem (posto) da \%casca, Tabela 3, Si & 3 & 2 & 8 & 5 & 4 & 6 & 7 & 1 \\
\hline$(\mathrm{Ri}-\mathrm{Sj})^{2}$ & 36 & 1 & 49 & 9 & 9 & 1 & 1 & 16 \\
\hline$\sum(\mathrm{Ri}-\mathrm{Sj})^{2}=\mathrm{D}$ & 138 & & & & & & & \\
\hline
\end{tabular}


O valor calculado para D foi 138 e na tabela da distribuição normal (Fisher e Yates, 1971), o valor de sua probabilidade de significância correspondente ao $\mathrm{z}=0,44$, é 0,33 , que é muito maior que 0,05 , o que não rejeita a hipótese de independência entre as variáveis. Portanto, tem-se que, para um nível de $5 \%$ de significância, a porcentagem de casca é independente do DAP.

Para estimação de alturas totais e comerciais e de volumes: comercial, adequado para serraria e de topos, foram obtidos modelos pela da aplicação da técnica "Jackfine" (Schreuder e Brinck, 1983). Esses modelos são válidos para o intervalo de diâmetros entre 40,0 e $55,0 \mathrm{~cm}$, e são os seguintes :

- Para estimativa da altura total, $\mathrm{Ht}$, expresso em m:

$\mathrm{Ht}=1,3+\left\{\mathrm{DAP}^{2} /\left[0,772+(1,338 * \mathrm{DAP})^{2}\right]\right\} \quad \mathrm{R}^{2}=0,968 \quad \mathrm{STD}(\mathrm{Y})=0,159$

- Para estimativa da altura comercial, Hc, expresso em m:

$\mathrm{Hc}=1,3+\left[\mathrm{DAP}^{2} /\left(-59,399+2,859 * \mathrm{DAP}-0,009 * \mathrm{DAP}^{2}\right)\right] \quad \mathrm{R}^{2}=0,942 \quad \mathrm{STD}(\mathrm{Y})=2,035$

- Para estimativa do volume comercial, $\mathrm{Vc}$, expresso $\mathrm{em}^{3}$ :

$\mathrm{Vc}=3,798 * 10^{-4} * \mathrm{DAP}^{2,34}$

$$
\mathrm{R}^{2}=0,896 \quad \mathrm{STD}(\mathrm{Y})=
$$

0,018

- Para estimativa do volume de madeira adequada para serraria, Vad, expresso $\mathrm{em}^{3}$ :

$\operatorname{Vad}=6,832 * 10^{-6} * \mathrm{DAP}^{3,318}$

$\mathrm{R}^{2}=0,873 \quad \operatorname{STD}(\mathrm{Y})=0,032$

- Para estimativa do volume de pontas de árvores, $\mathrm{Vp}$, expresso $\mathrm{em}^{3}$ :

$\mathrm{Vp}=4,938-0,171 * \mathrm{DAP}+1,685 * 10^{-3} * \mathrm{DAP}^{2} \quad \mathrm{R}^{2}=0,763 \quad \mathrm{STD}(\mathrm{Y})=0,068$

Como esperado, árvores com DAP maiores apresentaram os maiores volumes comerciais de madeira sem casca. O volume de madeira adequada para serraria diminuiu com as reduções do DAP, como visto na Figura 2.

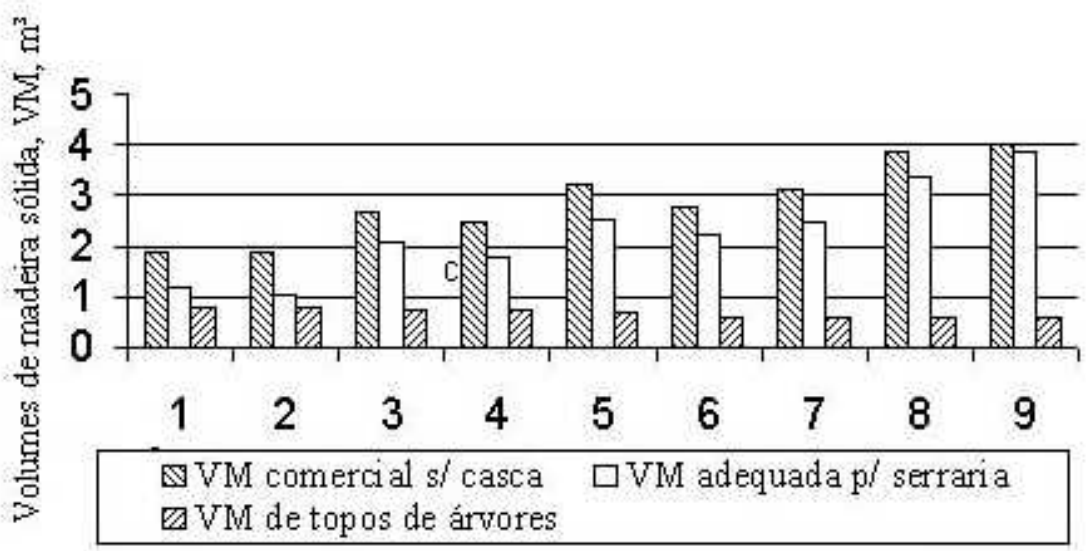

FIGURA 2: Volumes de madeira versus DAP (diâmetro à altura do peito).

FIGURE 2: Wood volume versus DBH (diameter breast height).

As árvores com DAP maiores que $30 \mathrm{~cm}$ foram cortadas em troncos com comprimento ou de 3 ou 6 m, conforme indicado na Figura 3.

Esses troncos foram serrados em tábuas, coletando-se os dados que estão na Tabela 5. O volume de resíduo de serraria também é apresentado nessa tabela. Conforme o tipo de amostra A, B ou C, têm-se, nessa tabela os volumes gerados de serragem e de cavacos que foram obtidos com os resíduos de serraria. Vê-se nesta tabela, que todos os valores são influenciados pelo DAP da madeira (Tabela 2).

Na Tabela 5, têm-se em média que $20,594 \mathrm{~m}^{3}$ de madeira sólida adequada para serraria geraram $10,208 \mathrm{~m}^{3}$ de tábuas, produzindo $9,732 \mathrm{~m}^{3}$ empilhados de serragem mais $12,9 \mathrm{~m}^{3}$ empilhados de resíduos de serraria que, por sua vez, geraram $17,1 \mathrm{~m}^{3}$ empilhados de cavacos. Esses dados, mais os anteriores, permitiram estabelecer as relações em volume que estão na Tabela 6 . 


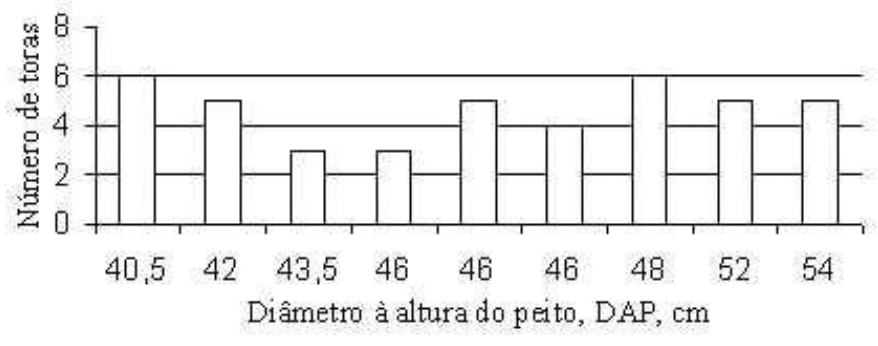

FIGURA 3: Número de toras em função do DAP das árvores.

FIGURE 3: Number of logs in function of the DBH.

TABELA 5: Dados obtidos na serraria.

TABLE 5: Sawmill data.

\begin{tabular}{c|c|c|c|c|c|c|c}
\hline $\begin{array}{c}\text { Código da } \\
\text { Árvore }\end{array}$ & $\begin{array}{c}\mathrm{N} . \\
\text { Toras }\end{array}$ & $\begin{array}{c}\text { DM } \\
(\mathrm{cm})\end{array}$ & $\begin{array}{c}\text { Volume de } \\
\text { Tábuas } \\
\left(\mathrm{m}^{3}\right)\end{array}$ & $\begin{array}{c}\text { Rendimento } \\
\text { da Serraria }^{1} \\
(\% \text { v/v })\end{array}$ & $\begin{array}{c}\text { Volume de } \\
\text { Serragem } \\
\left(\mathrm{m}^{3}\right)\end{array}$ & $\begin{array}{c}\text { VRS } \\
\left(\mathrm{m}^{3}\right)\end{array}$ & $\begin{array}{c}\text { VCG } \\
\left(\mathrm{m}^{3}\right)\end{array}$ \\
\hline A1 & 6,0 & 43,70 & 2,144 & 55,6 & 1,560 & 1,630 & \\
A2 & 5,0 & 37,60 & 0,859 & 41,5 & 1,091 & 1,410 & 5,6 \\
A3 & 3,0 & 34,60 & 0,573 & 49,1 & 0,499 & 0,810 & \\
\hline B1 & 3,0 & 33,50 & 0,559 & 53,0 & 0,525 & 0,940 & \\
B2 & 5,0 & 38,90 & 1,182 & 47,3 & 1,341 & 1,680 & 4,4 \\
B3 & 4,0 & 37,10 & 0,848 & 47,1 & 0,856 & 1,170 & \\
\hline C1 & 6,0 & 41,40 & 1,644 & 48,7 & 1,606 & 1,830 & \\
C2 & 5,0 & 38,90 & 1,307 & 51,8 & 1,194 & 1,520 & 7,1 \\
C3 & 5,0 & 37,60 & 1,092 & 48,7 & 1,060 & 1,300 & \\
\hline Média geral & 4,7 & 38,14 & 1,092 & 49,2 & 1,081 & 12,900 & - \\
Total & - & - & 10,208 & - & 9,732 & - & 17,1 \\
\hline
\end{tabular}

Em que: 1 = Baseados no volume comercial de madeira sem casca; $\mathrm{DM}=$ Diâmetro médio (maior que $30 \mathrm{~cm}$ ); VRS = volume de resíduo de serraria; $\mathrm{VCG}=$ Volume de cavacos gerados com os resíduos de serraria.

O volume de serragem obtido ( $9,732 \mathrm{~m}^{3}$ empilhados) foi muito maior que o valor citado por Foelkel et al (1978), mais próximo do informado por Perez Jara ( 1995 ) que ficaria entre 4,12 e 5,15 $\mathrm{m}^{3}$, mas muito menor que o valor citado por Casey (1980) que ficaria em $46,5 \mathrm{~m}^{3}$ empilhados. O volume de cavacos obtidos $\left(17,1 \mathrm{~m}^{3}\right.$ empilhados) foi cerca de um terço do valor citado por Fisher (1978) que ficaria em 51,5 $\mathrm{m}^{3}$ empilhados.

TABELA 6: Relações entre os dados de volumes coletados no campo e na serraria.

TABLE 6: Relations between the volume data collected in the field and in the sawmill.

\begin{tabular}{|c|c|c|c|c|c|c|c|}
\hline \multirow{2}{*}{$\begin{array}{l}\text { Madeira } \\
\text { Original } \\
\left(\mathrm{m}^{3} / \mathrm{m}^{3}\right) \\
\end{array}$} & \multirow{2}{*}{$\begin{array}{c}\text { Resíduo } \\
\text { Florestal } \\
\left(\mathrm{m}^{3} / \mathrm{m}^{3}\right)\end{array}$} & \multicolumn{2}{|c|}{ Madeira Comercial } & \multirow{2}{*}{$\begin{array}{l}\text { MAS } \\
\left(\mathrm{m}^{3} / \mathrm{m}^{3}\right)\end{array}$} & \multirow{2}{*}{$\begin{array}{l}\text { Tábuas } \\
\left(\mathrm{m}^{3} / \mathrm{m}^{3}\right)\end{array}$} & \multirow[t]{2}{*}{ Serragem $^{1}$} & \multirow[t]{2}{*}{ Cavacos } \\
\hline & & $\mathrm{c} / \mathrm{c}\left(\mathrm{m}^{3} / \mathrm{m}^{3}\right)$ & $\mathrm{s} / \mathrm{c}\left(\mathrm{m}^{3} / \mathrm{m}^{3}\right)$ & & & & \\
\hline 1 & 0,008 & 0,992 & 0,899 & 0,714 & 0,354 & 0,338 & 0,593 \\
\hline - & - & 1 & 0,906 & 0,720 & 0,357 & 0,340 & 0,598 \\
\hline - & - & - & 1 & 0,795 & 0,394 & 0,378 & 0,660 \\
\hline- & - & - & - & 1 & 0,495 & 0,475 & 0,830 \\
\hline
\end{tabular}

Em que: $\mathrm{c} / \mathrm{c}=$ com casca; $\mathrm{s} / \mathrm{c}=$ sem casca; $1=\mathrm{m}^{3} / \mathrm{m}^{3}$ de material empilhado; MAS = madeira adequada para serraria.

\section{Fase 2: Dados obtidos com as misturas}

\section{Densidade básica e elementos anatômicos}

Os dados de densidade básica e os elementos anatômicos obtidos com as misturas de cavacos estão na Tabela 7 e, na Tabela 8, estão as relações entre os diferentes elementos anatômicos. 
TABELA 7: Dados de densidade básica e elementos anatômicos.

TABLE 7: Basic density and anatomic elements data.

\begin{tabular}{l|c|c|c|c|c|c}
\hline \multirow{2}{*}{ Misturas } & Densidade & \multicolumn{2}{c|}{ Características Morfológicas das Fibras } & \multicolumn{2}{c}{ Vasos } \\
\cline { 3 - 7 } & $\begin{array}{c}\text { Básica } \\
\left(\mathrm{g} / \mathrm{cm}^{3}\right)\end{array}$ & $\begin{array}{c}\mathrm{C} \\
(\mathrm{mm})\end{array}$ & $\begin{array}{c}\mathrm{L} \\
\left(10^{-3} \mathrm{~mm}\right)\end{array}$ & $\begin{array}{c}\mathrm{E} \\
\left(10^{-3} \mathrm{~mm}\right)\end{array}$ & $\begin{array}{c}\text { Lúmen } \\
\left(10^{-3} \mathrm{~mm}\right)\end{array}$ & $\begin{array}{c}\mathrm{C} \\
(\mathrm{mm})\end{array}$ \\
\hline 1. Eg (Eucalyptusgrandis,7 anos industrial) $)$ & 0,408 & 1,14 & 20,78 & 3,96 & 12,86 & 12,43 \\
2. Topo & 0,502 & 1,09 & 21,88 & 4,51 & 12,94 & 8,69 \\
3. Resíduo de serraria & 0,424 & 1,14 & 20,08 & 4,47 & 11,14 & 10,08 \\
4. 2/3 Eg + 1/3 Topo & 0,448 & 1,04 & 20,31 & 4,04 & 12,24 & 9,04 \\
5. 1/3 Eg + 2/3 Topo & 0,489 & 1,19 & 19,92 & 4,18 & 11,61 & 7,93 \\
6. 2/3 Eg + 1/3 Resíduo de serraria & 0,417 & 1,18 & 20,31 & 4,2 & 12 & 10,36 \\
7. 1/3 Eg + 2/3 Resíduo de serraria & 0,423 & 1,2 & 21,33 & 4,2 & 12,94 & 9,76 \\
8. 2/3 Topo + 1/3 Res. de serraria & 0,475 & 1,16 & 20,71 & 3,84 & 13,02 & 8,8 \\
9. 1/3 Topo + 2/3 Res. de serraria & 0,483 & 1,23 & 19,69 & 4,08 & 11,53 & 9,69 \\
10.1/3 Eg + 1/3 Topo + 1/3 Res. serraria & 0,454 & 1,14 & 24,16 & 4,35 & 15,45 & 9,53 \\
\hline Valor Médio & 0,452 & 1,15 & 20,92 & 4,18 & 12,57 & 9,63 \\
\hline
\end{tabular}

Em que: $\mathrm{C}=$ Comprimento; $\mathrm{L}=$ Largura; $\mathrm{E}=$ Espessura da parede.

O valor médio da densidade básica foi de $0,452 \mathrm{~g} / \mathrm{cm}^{3}$, valor abaixo do desejado pela indústria em geral, que é de $0,5 \mathrm{~g} / \mathrm{cm}^{3}$, entretanto, verificou-se que a própria madeira industrial apresentou um valor ainda mais baixo $(0,408$ $\mathrm{g} / \mathrm{cm}^{3}$ ) e que esse valor aumentou quando se misturou as outras partes das árvores com 15 anos de idade. $\mathrm{O}$ topo das árvores com 15 anos é que apresentou os maiores resultados, seguido pelos valores referentes aos resíduos de serraria e, em último, pelos valores da madeira de 7 anos. Esses resultados concordam com aqueles observados por Barrichello et al. (1986), Foelkel et al. (1971) e Manfredi (1985). A tendência de evolução dessa propriedade em função da composição das misturas pode ser melhor observada na Figura 4.

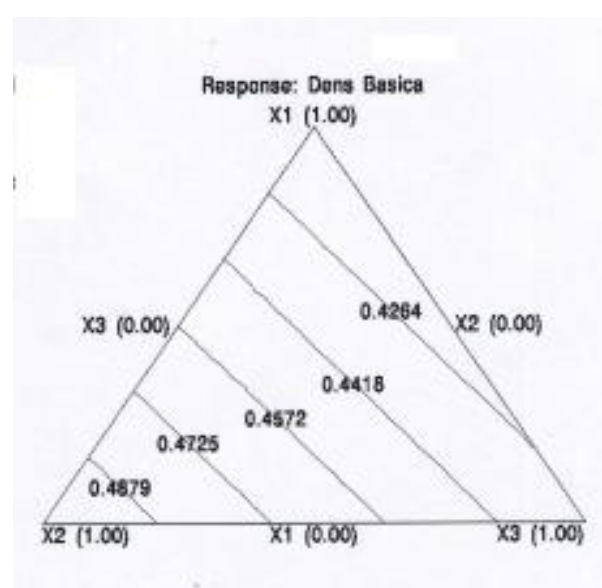

A

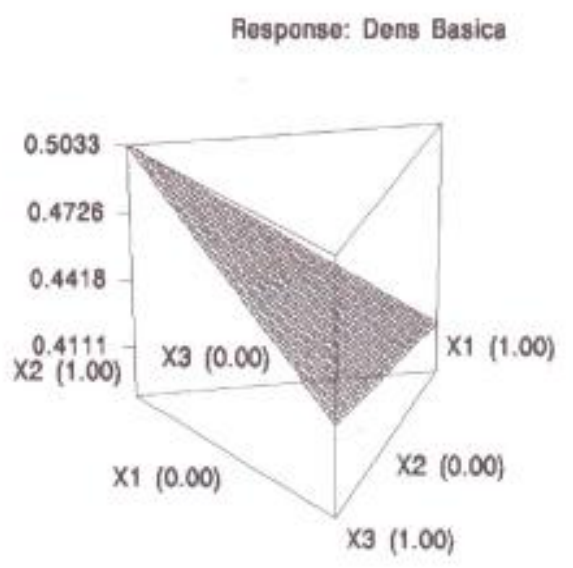

B

FIGURA 4: Densidade básica ( $\mathrm{Y})$ em função da composição das misturas $(\mathrm{X} 1=$ Eg7anos; $\mathrm{X} 2=$ topos; $\mathrm{X} 3=$ resíduo de serraria. Figura A, 2D; Figura B, 3D. $Y=0,411 * \mathrm{X}_{1}+0,5033 * \mathrm{X}_{2}+0,4299 * \mathrm{X}_{3}$ $\left(\mathrm{R}^{2}=0,975\right)$.

FIGURE 4: Basic density (Y) in function of the mixtures composition.

Da Tabela 7, pode-se extrair que as fibras do resíduo de serraria são mais longas e menos largas que as do topo e do Eucalyptus grandis com 7 anos, apresentando todas praticamente o mesmo diâmetro de lúmen. Assim, as fibras do resíduo devem contribuir mais que as outras para aumentar a resistência mecânica da pasta. Já os elementos de vasos são mais compridos que os do Eucalyptus grandis com 7 anos, seguidos pelos 
do resíduo e em último pelos do topo, mas entre eles essa diferença é pequena, podendo-se extrair que interferem de modo semelhante na porosidade do papel.

Na Figura 5, em que os valores de poder de enfeltramento, PE, são contrastados com os da relação de flexibilidade, RF, vê-se que só a mistura 10 caiu fora do quadrante com valores mais altos que 50, em PE, e com mais de 50\%, em RF. De acordo com Philipp (1974), há fortes indícios de que as pastas resultantes dessas misturas apresentem valores satisfatórios de resistência à tração e ao rasgo. Somente pasta resultante da mistura 10 é que deve apresentar resistências à tração e ao rasgo moderadas.

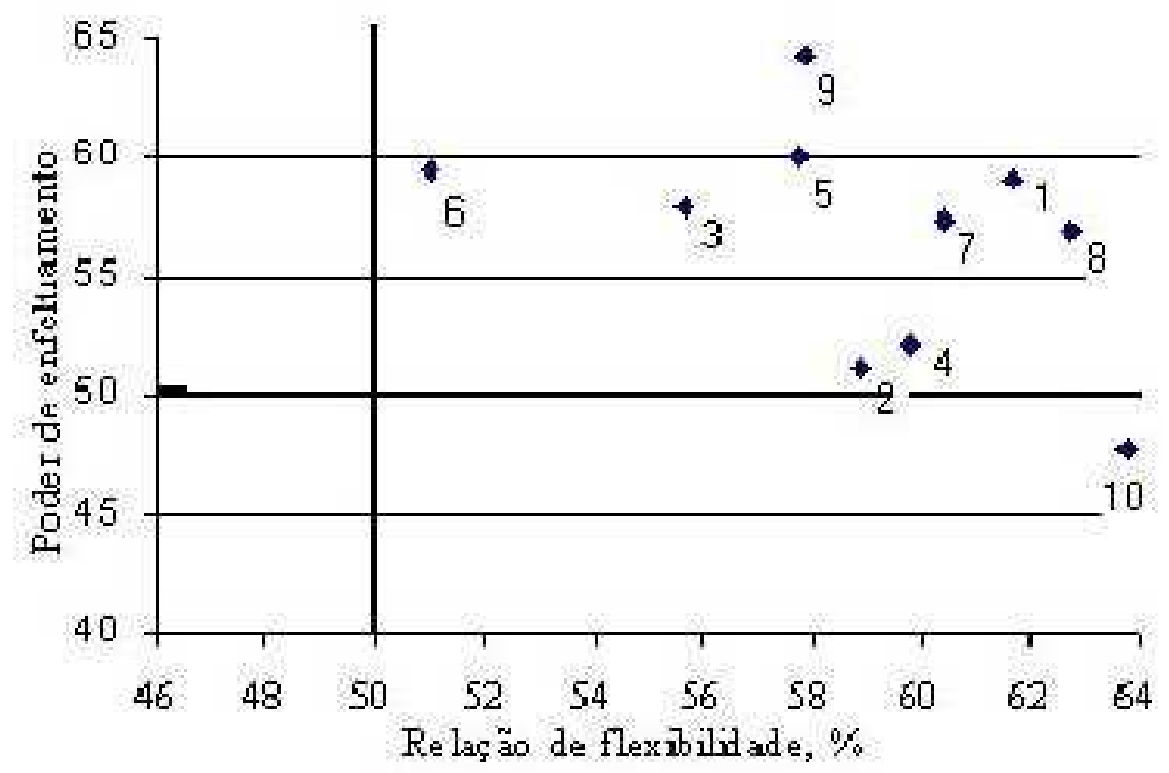

FIGURA 5: Relação de flexibilidade versus poder de enfeltramento.

FIGURE 5: Flexibility relation versus felting power.

TABELA 8: Relações entre os elementos anatômicos.

TABLE 8: Anatomic elements relationship.

\begin{tabular}{|c|c|c|c|c|}
\hline Misturas & $\begin{array}{c}\text { Poder de } \\
\text { Enfeltramento }\end{array}$ & $\begin{array}{l}\text { Relação de } \\
\text { Flexibilidade } \\
\text { (\%) }\end{array}$ & $\begin{array}{c}\text { Fração de } \\
\text { Parede } \\
(\%)\end{array}$ & $\begin{array}{l}\text { Índice de } \\
\text { Runckel }\end{array}$ \\
\hline 1. Eg (Eucalyptus grandis, 7 anos, industrial) & 59,12 & 61,67 & 38,33 & 0,65 \\
\hline 2. Торо & 51,12 & 58,91 & 41,25 & 0,72 \\
\hline 3. Resíduo de serraria (costaneiras) & 57,82 & 55,66 & 44,34 & 0,85 \\
\hline 4. $2 / 3 \mathrm{Eg}+1 / 3$ Topo & 52,11 & 59,82 & 40,18 & 0,69 \\
\hline 5. $1 / 3 \mathrm{Eg}+2 / 3$ Topo & 60,00 & 57,78 & 42,22 & 0,81 \\
\hline 6. $2 / 3 \mathrm{Eg}+1 / 3$ Res. serraria & 59,47 & 51,00 & 41,76 & 0,94 \\
\hline 7. $1 / 3 \mathrm{Eg}+2 / 3$ Res. serraria & 57,31 & 60,41 & 37,93 & 0,70 \\
\hline 8. $2 / 3$ Topo + 1/3 Res. serraria & 56,96 & 62,76 & 37,24 & 0,62 \\
\hline 9. 1/3 Topo + 2/3 Res. serraria & 64,38 & 57,89 & 42,11 & 0,78 \\
\hline 10.1/3 Eg +1/3 Topo+ 1/3 Res. serraria & 47,71 & 63,80 & 36,20 & 0,58 \\
\hline Média global & 56,60 & 58,97 & 40,16 & 0,73 \\
\hline
\end{tabular}

Os dados obtidos para a maioria das misturas atendem aos pré-requisitos de densidade básica; os índices de Runckel são inferiores a 1; o comprimento médio das fibras pode aumentar com a inclusão de madeira de resíduo de serraria (Figura 6); as frações de parede (Figura 7) ficam próximas dos 40\%; indicando que ao se misturar cavacos de resíduo de serraria e de topo com cavacos industriais de Eucalyptus grandis com 7 anos, a qualidade final da pasta kraft resultante não deve se alterar muito, podendo até melhorar. 


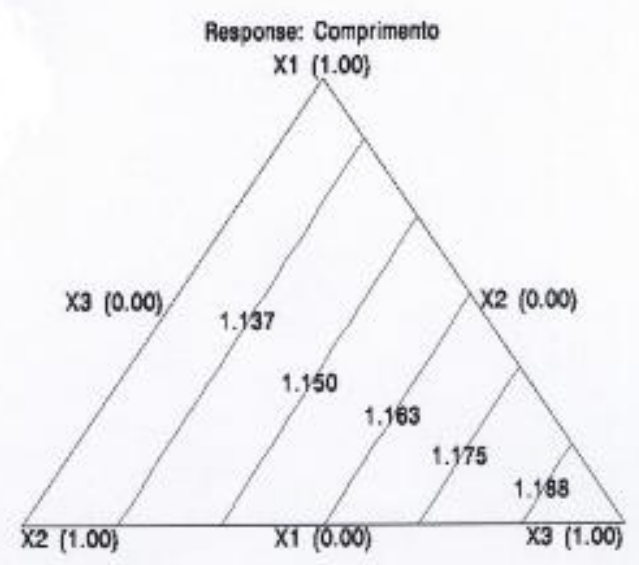

A

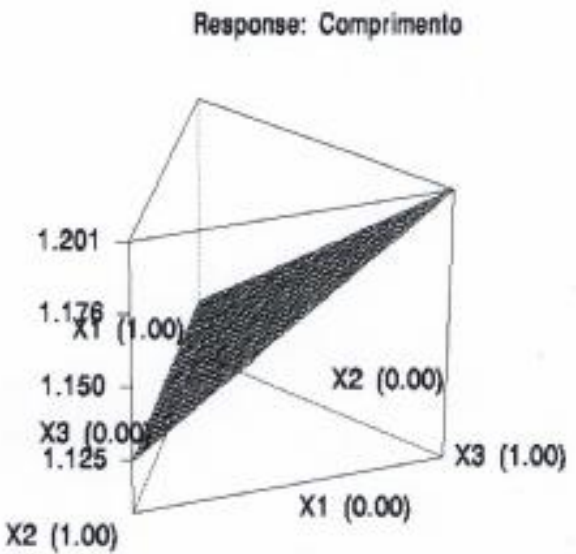

B

FIGURA 6: Comprimento de fibra (Y) em função da composição das misturas. X1 = Eg7anos; X2 = topo; $\mathrm{X} 3=$ resíduo de serraria. Figura A, 2D; Figura B, 3D. $Y=1,127 * \mathrm{X}_{1}+1,125 * \mathrm{X}_{2}+1,201 *$ $\mathrm{X}_{3} \quad\left(\mathrm{R}^{2}=0,928\right)$.

FIGURE 6: Fiber lenghts (Y) in function of the wood mixtures composition.

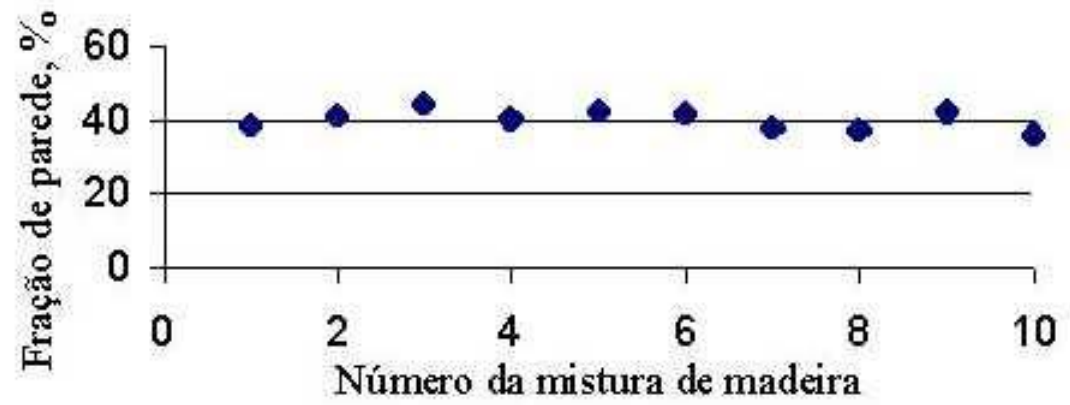

FIGURA 7: Valores de fração de paredes das misturas de madeiras.

FIGURE 7: Wall fractions values for the wood mixtures

\section{Caracterização química das misturas}

Os dados de caracterização química das misturas estão na Tabela 9, em que se vê que, para o resíduo de serraria, a lignina tem valores levemente mais altos; holocelulose, menor e as solubilidades em água quente, etanol e $\mathrm{NaOH} 1 \%$ são menores. A madeira do topo e a do Eucalyptus grandis com 7 anos apresentam valores praticamente semelhantes de lignina, holocelulose e solubilidades em água quente e em etanol, mas a de topo apresenta valores de solubilidade em $\mathrm{NaOH} 1 \%$ levemente mais altos.

Pela literatura, já se esperava que as características químicas do resíduo de serraria, com características mais de madeira juvenil, e do topo, com características de madeira adulta, fossem diferentes das da madeira industrial. Entretanto, em termos práticos pode significar apenas um leve acréscimo no consumo de reagentes durante o cozimento quando se processa misturas com alto conteúdo de topos. 
TABELA 9: Características químicas de misturas de madeira.

TABLE 9: Chemical characteristics of the wood mixtures.

\begin{tabular}{l|ccc|c|c|c}
\hline \multicolumn{1}{c|}{ Misturas } & \multicolumn{2}{c|}{$\begin{array}{c}\text { Solubilidade } \\
(\%)\end{array}$} & $\begin{array}{c}\text { Lignina } \\
\text { Klason } \\
(\%)\end{array}$ & $\begin{array}{c}\text { Holo- } \\
\text { celulose } \\
(\%)\end{array}$ & $\begin{array}{c}\text { Teor de } \\
\text { Cinzas } \\
(\%)\end{array}$ \\
\hline 1. Eg (Eucalyptus grandis, 7 anos, Industrial) & 3,3 & 12,6 & 4,2 & 24,6 & 70,9 & 0,3 \\
2. Topo & 3,4 & 13,8 & 3,8 & 24,4 & 70,6 & 1,1 \\
3. Resíduo de serraria ( costaneiras) & 2,6 & 11,7 & 3,9 & 25,1 & 69,9 & 1,1 \\
4. 2/3 Eg + 1/3 Topo & 7,2 & 17,0 & 8,3 & 23,8 & 67,6 & 0,3 \\
5. 1/3 Eg + 2/3 Topo & 6,4 & 15,6 & 6,9 & 24,7 & 68,2 & 0,2 \\
6. 2/3 Eg + 1/3 Res. serraria & 6,1 & 15,6 & 6,5 & 23,9 & 69,3 & 0,3 \\
7. 1/3 Eg + 2/3 Res. serraria & 4,0 & 13,2 & 4,5 & 25,2 & 70,1 & 0,2 \\
8. 2/3 Topo + 1/3 Res. serraria & 4,8 & 13,8 & 5,6 & 25,2 & 69,0 & 0,1 \\
9. 1/3 Topo + 2/3 Res. serraria & 3,7 & 12,9 & 3,7 & 25,2 & 70,9 & 0,2 \\
10. 1/3 Eg+1/3 Topo+1/3 Res.serraria & 5,2 & 14,8 & 5,9 & 24,3 & 89,8 & 0,2 \\
\hline Média global & 4,7 & 14,1 & 5,3 & 24,6 & 71,6 & 0,4 \\
\hline
\end{tabular}

\section{Polpação kraft}

A Tabela 10 apresenta os resultados médios de rendimento bruto em pasta não-depurada e de números Kappa obtidos nas deslignificações kraft das misturas. Apresenta também os dados calculados de consumo específico de madeira sólida, estimados para uma produção-padrão de $1.000 \mathrm{t}$ de pasta seca ao ar por dia. Nas Figuras 8, 9 e 10, apresentam-se os iso-valores dessas propriedades em função da composição de misturas.

TABELA 10: Resultados de rendimento bruto em pasta, número Kappa e consumo específico de madeira sólida para uma produção $1.000 \mathrm{t}$ de pasta seca ao ar por dia.

TABLE 10: Values of pulp gross yield, Kappa number and specific solid wood consumption for a mill production of $1.000 \mathrm{t}$ of air dry pulp per day.

\begin{tabular}{|c|c|c|c|}
\hline Misturas & $\begin{array}{l}\text { Rendimento } \\
\text { Bruto }^{\mathrm{a}} \\
(\%)\end{array}$ & Número Kappa & $\begin{array}{c}\text { Consumo de Madeira } \\
\text { sólida/t } \mathrm{psa}^{\mathrm{b}} \\
\left(\mathrm{m}^{3}\right)\end{array}$ \\
\hline 1. Eg (Eucalyptus grandis, 7 anos, industrial) & 53,05 & 20,0 & 4,62 \\
\hline 2. Торо & 50,91 & 21,0 & 3,91 \\
\hline 3. Resíduo de serraria & 52,39 & 18,0 & 4,50 \\
\hline 4. $2 / 3 \mathrm{Eg}+1 / 3$ Tоро & 54,17 & 23,3 & 4,14 \\
\hline 5. $1 / 3 \mathrm{Eg}+2 / 3$ Topo & 53,24 & 22,0 & 4,00 \\
\hline 6. $2 / 3 \mathrm{Eg}+1 / 3$ Res. serraria & 54,55 & 20,1 & 4,40 \\
\hline 7. $1 / 3 \mathrm{Eg}+2 / 3$ Res. serraria & 53,96 & 21,2 & 4,38 \\
\hline 8. 2/3 Topo+ 1/3 Res. serraria & 52,24 & 19,2 & 4,03 \\
\hline 9. 1/3 Topo + 2/3 Res. serraria & 52,31 & 19,5 & 4,13 \\
\hline 10. $1 / 3 \mathrm{Eg}+1 / 3$ Topo + 1/3 Res. serraria & 52,49 & 19,1 & 4,20 \\
\hline Média global & 52,93 & 20,3 & 4,23 \\
\hline
\end{tabular}

Em que: $($ a) $=$ (massa seca de pasta/massa seca de cavacos de madeira) $100 ;(b)=$ Igual a $(1000 \mathrm{t}$ pasta seca ao ar/rendimento bruto)/(densidade básica). 

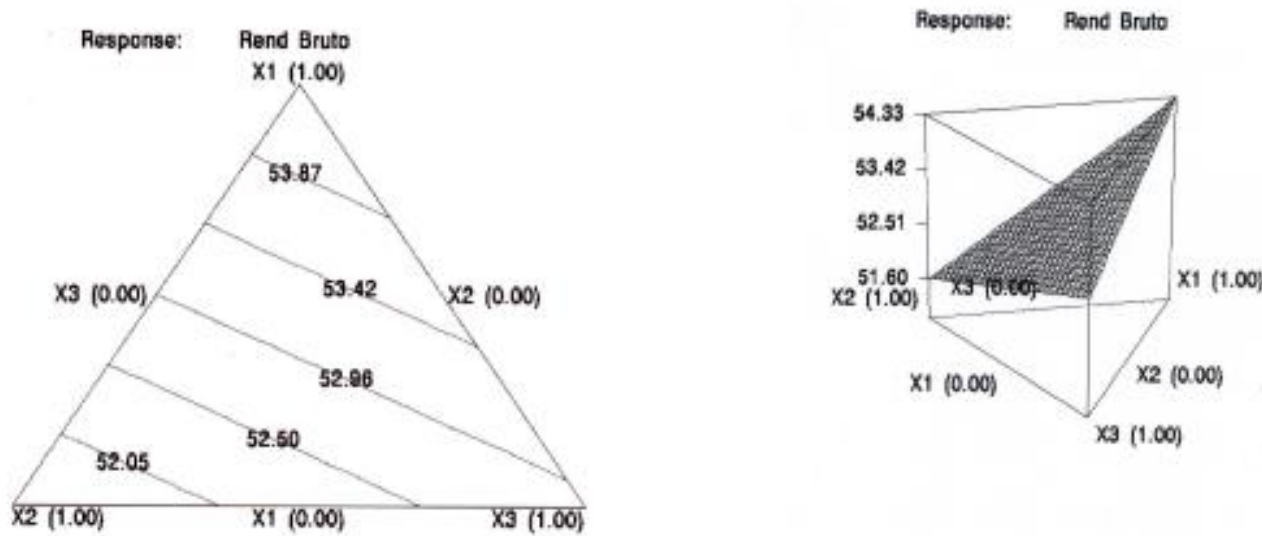

B

FIGURA 8: Rendimento bruto (Y) em função da composição das misturas. X1 = Eg7anos; X2 = topo; X3 = resíduo de serraria (costaneiras e resíduo). Figura A, 2D; Figura B, 3D. $\mathrm{Y}=7,371 * \mathrm{X}_{1}+7,183 * \mathrm{X}_{2}+7,211 * \mathrm{X}_{3} \quad\left(\mathrm{R}^{2}=0,577\right)$.

FIGURE 8: Gross yield $(\mathrm{Y})$ in function of the wood mixtures composition.

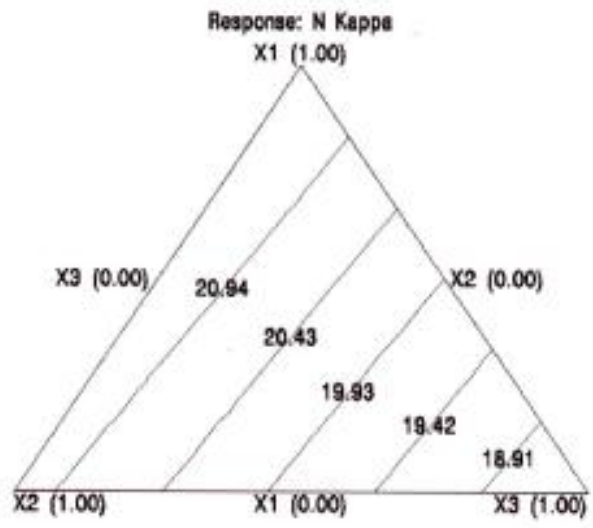

A

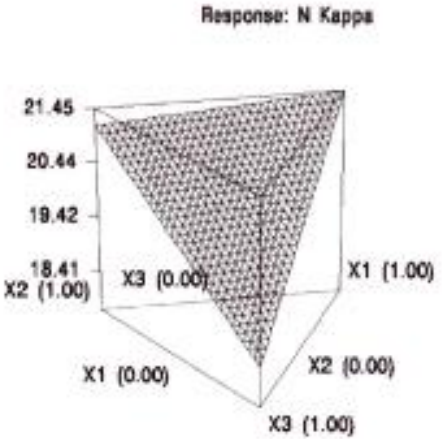

B

FIGURA 9: Número Kappa (Y) em função da composição das misturas. $\mathrm{X} 1=$ Eg7anos, $\mathrm{X} 2=$ topo; $\mathrm{X} 3=$ resíduo de serraria (costaneiras e resíduo). Figura A, 2D; Figura B, 3D. $\mathrm{Y}=21,45 * \mathrm{X}_{1}+21,13 * \mathrm{X}_{2}+18,41 * \mathrm{X}_{3} \quad\left(\mathrm{R}^{2}=0,424\right)$.

FIGURE 9: Kappa number in fuction of the wood mixtures composition.

$\mathrm{Na}$ Figura 8, vê-se que os valores de rendimento bruto em pasta obtidos com o Eucalyptus grandis com 7 anos foram bem superiores aos obtidos com o resíduo de serraria, os quais foram só um pouco diferentes dos apresentados pelos topo das árvores.

Para números Kappa, a Figura 11 mostra que, para o Eucalyptus grandis com 7 anos, os valores diminuem um pouco com a inclusão da madeira de topo, mas muito mais quando se inclui o resíduo de serraria. Isto indica que o acréscimo de material juvenil é mais fácil de se deslignificar. Assim, para um mesmo número Kappa, as condições de cozimento podem ser menos drásticas, o que se refletirá tanto no consumo de reagentes do processo como no consumo específico de madeira sólida (Figura 11). Portanto, conclui-se desta que a inclusão tanto de resíduo de serraria como de topos nas misturas não contribui negativamente para o consumo específico de madeira sólida. 


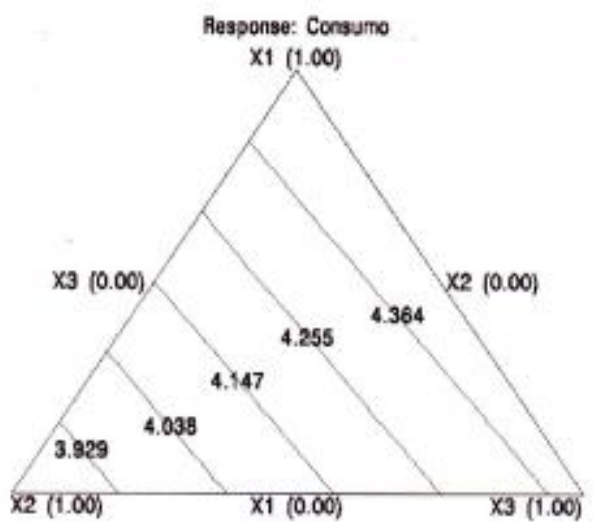

A

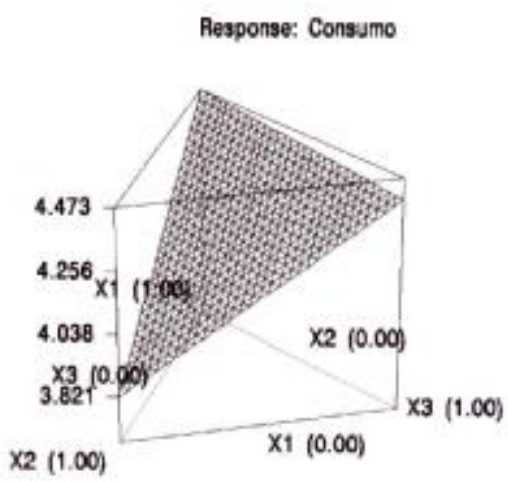

B

FIGURA 10: Consumo específico de madeira sólida ( $\mathrm{Y}$ ) em função da composição das misturas. X1 = Eg7anos, $\mathrm{X} 2$ = topo; $\mathrm{X} 3$ = resíduo de serraria (costaneiras e resíduo). Figura A, 2D; Figura B, 3D. $Y=4,473 * X_{1}+3,821 * X_{2}+4,399 * X_{3} \quad\left(R^{2}=0,866\right)$.

FIGURE 10: Specific consumption of solid wood (Y) in funtion of the wood mixtures composition.

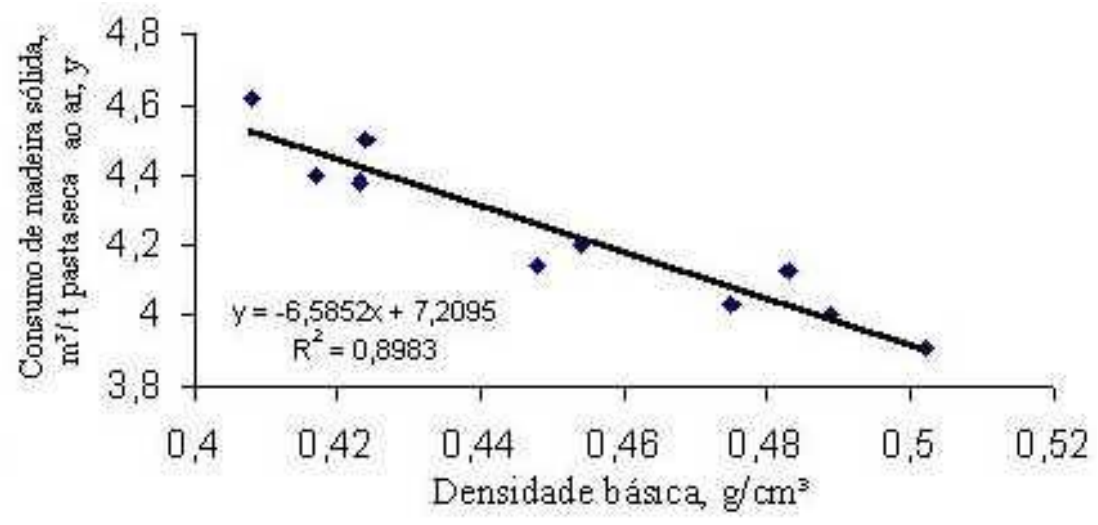

FIGURA 11: Consumo de madeira sólida versus densidade básica.

FIGURE 11: Solid wood consumption versus basic density.

Manfredi (1985) associou um rendimento bruto maior com a madeira com densidade básica menor. Os dados que constam da Tabela 10 também sugerem isso, mas sua análise mostrou uma correlação muito fraca entre estas variáveis $\left(\mathrm{R}^{2}=0,3925\right)$. A correlação entre densidade e número Kappa praticamente não existe $\left(\mathrm{R}^{2}=0,0379\right)$. Já o consumo específico de madeira sólida mostrou que se correlaciona em ordem inversa aos valores de densidade básica $\left(R^{2}=-0,8933\right)$, conforme mostra a Figura 11, sugerindo que quando a densidade básica aumenta, diminui a madeira necessária para produzir uma tonelada de pasta.

\section{CONCLUSÕES}

Os resultados obtidos permitem extrair as seguintes conclusões:

A madeira de eucalipto com 15 anos de idade apresenta um volume de resíduo de floresta da ordem de $0,85 \%$ do volume total das árvores.

O conteúdo de casca variou entre 7 e 10,2\%, mostrando uma independência estatística do DAP. E foram estabelecidas relações baseadas no DAP para estimação de alturas total e comercial e dos volumes: comercial, o adequado para serraria e o de topos. 
Os troncos serrados apresentaram um rendimento em tábuas de 52,3\%. Baseado no volume de madeira sólida adequada para serraria, a produção de tábuas foi de 1:0,7, gerando 1:0,72 de serragem e de 1:2,12 de cavacos resultantes dos resíduos de serraria (costaneiras e resíduos).

A madeira dos resíduos de serraria apresenta um maior teor de lignina e menor de extrativos em água quente e solubilidade em $\mathrm{NaOH} 1 \%$ que o Eucalyptus grandis com 7 anos. A madeira dos topos das árvores apresenta os menores teores de extrativos e solubilidades em água quente e em $\mathrm{NaOH} 1 \%$, mas densidade básica maior.

É tecnicamente viável realizar deslignificações kraft com misturas contendo madeira comercial de Eucalyptus grandis com 7 anos e resíduos de serraria ou topos de árvores. A deslignificação kraft de resíduos de serraria resulta em perda rápida de rendimento, mas a pasta produzida sob as mesmas condições apresenta número Kappa menor que a de Eucalyptus grandis com 7 anos. A deslignificação de topos das árvores resulta em perda de rendimento bruto, mas o consumo específico de madeira é menor.

Conforme aumenta a inclusão de madeira de topo das árvores com 15 anos de idade nas misturas com Eucalyptus grandis com 7 anos, ocorre um aumento na densidade básica, o comprimento médio das fibras fica praticamente o mesmo e um pequeno aumento no teor de lignina; há diminuição nos extrativos em etanol, em água quente e na solubilidade em $\mathrm{NaOH} 1 \%$. Diminue um pouco o rendimento bruto em pasta, mas praticamente não afeta o grau de deslignificação da pasta (número Kappa), caindo sensivelmente o consumo específico de madeira.

Com o aumento da quantidade de madeira de resíduo de serraria das árvores com 15 anos de idade nas misturas com Eucalyptus grandis com 7 anos, praticamente não há efeito sobre a densidade básica, mas o comprimento médio das fibras aumenta, ocorrendo também um pequeno aumento no teor de lignina. Os extrativos em etanol, em água quente e na solubilidade em $\mathrm{NaOH} 1 \%$ diminuem. O rendimento bruto em pasta cai um pouco, mas com uma queda sensível no grau de deslignificação da pasta (número Kappa), sem afetar praticamente o consumo específico de madeira. Em suma, para um mesmo grau de deslignificação (número Kappa), as condições de cozimento podem ser menos drásticas para se obter um mesmo resultado final, podendo isso significar uma redução no consumo de reagentes durante seu processamento. E como o comprimento médio das fibras sofreu um pequeno acréscimo, a pasta resultante certamente apresentará maior resistência mecânica e, conseqüentemente, um papel de melhor qualidade.

\section{AGRADECIMENTOS}

Os autores agradecem à Empresa RIOCELL (Guaíba/RS) e os Pesquisadores Celso E. B. Foelkel e Rubens Dias Humphreys pela colaboração na execução deste trabalho.

\section{REFERÊNCIAS BIBLIOGRAFICAS}

BARRICHELLO, L. E. G.; BRITO, J. O.; MIGLIORINI, A. J. Estudo da variação longitudinal da densidade básica de Eucalyptus spp. In: CONGRESSO FLORESTAL BRASILEIRO, 4., 1986, São Paulo. Anais... São Paulo, 1986. p.726-731.

CASEY , J, C. (Ed.) Pulp and paper chemistry and chemical technology . 3. ed. New York: John Wiley \& Sons, 1980.

ESTEP, E. M. Wood residue: what and where. Madison: FPRS, 1973. 14 p.

FOELKEL, C.E.B.; BRASIL, M.A.M.; BARRICHELLO, L.E.G. Métodos para determinação da densidade básica de cavacos para coníferas e folhosas. IPEF, v. 213, p. 65-74, 1971.

FOELKEL, C.E.B.; BARRICHELLO, L.E.G. Avaliação das madeiras para produção de celulose através de suas características estruturais: uma referência especial para o gênero Eucalyptus. IN: SEMINÁRIO DE INTEGRAÇÃO FLORESTA-INDÚSTRIA, 1975, Piracicaba. Anais... Piracicaba:IPEF, 1975. 180p. p.5-33.

FOELKEL, C.E.B.; ZVINAKEVICIUS, C.; ANDRADE,J. R. O cancro do eucalipto e sua influência sobre a qualidade da celulose kraft. CENIBRA Pesquisa, Belo Horiente, MG, v. 58, p. 1-34, maio 1978.

FOELKEL, C.E.B. Madeira do eucalipto: da floresta ao digestor. IPEF, Piracicaba, v.6, n. 20, p. E1-25, nov. 1978. 
FOREST PRODUCTS LABORATORY. Uses for sawdust and shavings. Madison, 1964. 5p. (EPL 047).

FISHER, G.; VOITH - Informações particulares. 1978.

FISHER, R.A.; YATES, F. Tabelas estatísticas para pesquisa em Biologia, Medicina e Agricultura. São Paulo: Ed. Polígono, 1971.

HATTON, J. V. Pulping and papermaking properties of managed second-growth softwoods. TAPPI J., Atlanta, v. 80, n. 1, p. 178-184, 1997.

HILLIS, W.E.; BROWN, A.G. Eucalyptus for wood production. Melbourne: CSIRO Academic Press, 1984. 434p.

JANKOWSKY, I.P. Madeira juvenil: formação e aproveitamento industrial. IPEF Série Técnica, Piracicaba, n. 81, p. 1-18., dez. 1979.

LEHMANN, E. L.; D'ABRERA, H. J. M. Nonparametrics: statistical methods based on ranks. New York: McGraw Hill International Book, 1975. 457 p.

MANFREDI, V.Variação do rendimento em celulose sulfato ao longo do tronco do Eucalyptus grandis Hill ex maiden e Eucalyptus saligna Smith. 1985. 94p. Dissertação (Mestrado) - Escola Superior de Agricultura "Luiz de Queiroz", Piracicaba, 1985.

NEVES, J. M. Informações particulares. 1980.

PANSHIN, A. J.; ZEEUW, C. Textbook of wood technology: structure, identification, uses, and properties of the commercial woods of the United States and Canada. 3. ed. New York: McGraw-Hill Book, 1970. 705p.

PEREZ JARA, E. Arquivo particular. 1995.

PHILIPP, P. Relações entre estrutura morfológica de fibras e propriedades de folhas manuais. In: CONGRESSO ANUAL CELULOSE E PAPEL, 7., 1974, São Paulo. Trabalhos técnicos ... São Paulo: ABTCP, 1974. p. 93-97.

SCHREUDER, H.T.; BRINK, G. E. The jacknife: a useful statistical tool. In: INTERN. CONF. OF RENEWABLE RESOURSES INVENTORIES FOR MONITORING CHANGES AND TRENDS, 1983, Corvalis, Oregon, USA. Proceedings ... Corvalis, 1983. p. 531-535. 